\title{
ENDOSCOPIC HOLMIUM:YAG LASER DACRYOCYSTORHINOSTOMY
}

\author{
S. A. SADIQ ${ }^{1}$, C. E. HUGKULSTONE ${ }^{1}$, N. S. JONES ${ }^{2}$ and R. N. DOWNES ${ }^{1}$ \\ Nottingham
}

\begin{abstract}
SUMMARY
The early results of the first 50 primary endonasal laser dacryocystorhinostomies in 49 patients performed with the holmium:YAG laser are presented. Overall, 35 $(\mathbf{7 0} \%)$ were successful in relieving symptoms of nasolacrimal obstruction after a mean follow-up period of 4 months. This improved to $79 \%$ in the subgroup of patients who underwent intubation of the naso-lacrimal system. These results were similar to the results of a retrospective study of 67 patients undergoing conventional dacryocystorhinostomy in our unit. Conventional surgery was performed under general anaesthesia in all but 1 case and all were treated as inpatients, with a mean hospital stay of 2.3 days, whereas all but 1 of the laser group had their surgery under local anaesthesia and 46 operations $(94 \%)$ were performed as an outpatient procedure. Surgery was significantly quicker with the endonasal laser technique and $90 \%$ of patients questioned found this technique to be entirely acceptable.
\end{abstract}

Ninety-one years ago, Toti ${ }^{1}$ described the technique of external dacryocystorhinostomy (DCR) to relieve obstruction of the lacrimal drainage system. This has become the procedure of choice for primary surgery, with success rates between $80 \%$ and $99 \% .^{2-10}$

The intranasal approach was first reported over 100 years ago, ${ }^{11}$ and recently attention has returned to this technique, utilising lasers to create the ostium. $^{12-16}$ Initially, an argon laser was employed $^{12,13}$ and then the carbon dioxide and potassium titanyl phosphate (PTP) lasers were investigated. ${ }^{14}$ Subsequently, one group has reported the use of the holmium:YAG laser. ${ }^{15,16} \mathrm{We}$ present the initial results of a prospective study of the first 50 cases undergoing primary holmium:YAG

From: Departments of ${ }^{1}$ Ophthalmology and ${ }^{2}$ Otorhinolaryngology, University Hospital, Nottingham NG7 2UH, UK.

Correspondence to: C. E. Hugkulstone, FRCSEd, FRCOphth, Department of Ophthalmology, Queen Mary's Hospital, Sidcup, Kent DA14 6LT, UK. laser endoscopic laser DCR (ELDCR) in our unit, and compare them retrospectively with the results in a group undergoing conventional external DCR.

\section{METHODS}

\section{Endoscopic Laser DCR}

Consecutive patients who required primary drainage surgery to relieve naso-lacrimal obstruction (as evidenced by epiphora, mucocoele or a history of acute dacryocystitis) between July 1993 and March 1994 were recruited to this study. All patients gave written consent to the procedure. Pre-operatively, a history was taken and a routine ophthalmic examination was performed. Probing and syringing of the naso-lacrimal system was performed and patients with common canalicular occlusion excluded.

Age, sex and indications for surgery were noted. All procedures were undertaken by the same surgeons (N.S.J. and R.N.D.). Surgery was performed under local anaesthesia (LA), except in one patient. Topical amethocaine $1 \%$ was instilled into the conjunctival fornices, and xylocaine $2 \%$ with 1:200 000 adrenaline was injected into both upper and lower lids around the canaliculi and infiltrated medially around the naso-lacrimal sac. A nasal pack soaked in $4 \%$ cocaine with sodium bicarbonate was inserted and left in situ for approximately 10 minutes. The patient was then prepared for surgery and the nasal pack removed.

Following canalicular dilatation, a 20 gauge vitreoretinal light probe was inserted in the upper canaliculus and advanced into the naso-lacrimal sac. The light was directly visualised endonasally with a $0^{\circ}$ nasal endoscope. The laser energy was delivered via a $15^{\circ}$ probe, aimed at the light. For mucosal ablation, the laser was set at a pulse energy of $0.6 \mathrm{~J}$ with a frequency of $10 \mathrm{~Hz}$. When bone was reached, the energy was increased to $1.0 \mathrm{~J}$ (at the same frequency) and was used to vaporise the bone. Once an ostium had been created, indicated by passage of the light probe into the nasal cavity, it was enlarged until easy 
passage of the probe was obtained. Patients received stents in a random fashion. This was performed with silicone tubes passed with the aid of an Abbocath (Venisystems, Abbott, Ireland) intravenous cannula and retrieved from the nose with fine nasal forceps. These were then secured with a Watzke sleeve plus a $6 / 0$ black silk suture. A fine-bore sucker was placed in the nostril to remove smoke produced during tissue ablation. Operative details, including anaesthesia, laser energy, per-operative complications and operation time, were recorded.

Post-operatively, patients were treated with a 2 week course of topical chloramphenicol drops and systemic antibiotics if indicated. Nasal douches were not employed. Patients were seen at 2 weeks postoperatively and thereafter as necessary. At the first post-operative visit, patients were asked their opinion of the acceptability of the procedure, and their symptoms were assessed at the final visit recorded in the case-notes. Follow-up was defined as the time from surgery until the final visit.

\section{Conventional DCR}

All patients who underwent conventional external DCR in this unit between January 1991 and December 1992 were identified from theatre records and their case-notes obtained. Age, sex and indications for surgery were noted. Surgical details and the duration of hospital stay were recorded. The operation time was assessed from the anaesthetic notes. Post-operatively, their symptoms were noted at the final visit and follow-up was defined as for the ELDCR group.

Results are given as mean (SD) unless otherwise noted. Mean values are compared with the unpaired $t$-test, and frequencies are analysed with the chisquared test (with Yates' correction for small numbers where appropriate) or Fisher's exact probability test.

\section{RESULTS}

\section{Endoscopic Laser DCR}

Forty-nine patients underwent 50 ELDCRs (1 patient undergoing bilateral surgery). There were 20 men and 29 women and their mean age was 65.8 (16.1) years. The indications for surgery are shown in Table I. Forty-six (94\%) had surgery performed as a daycase; 2 required an overnight stay for social reasons. One patient opted for a general anaesthetic, but the other 48 (98\%) had surgery under LA.

The average amount of local anaesthetic used was $5.9 \mathrm{ml}$. The mean operative time was 20.9 (14.8) minutes and the mean energy employed was $0.64 \mathrm{~kJ}$. Per-operative complications occurred in $13(26 \%)$ procedures; 10 of these were related to technical difficulties. Two patients suffered a transient medial rectus palsy as a result of the LA and 1 patient
Table I. Indications for surgery

\begin{tabular}{|c|c|c|}
\hline Indication & $\begin{array}{l}\text { Laser } \\
\text { DCR }\end{array}$ & $\begin{array}{c}\text { Conventional } \\
\text { DCR }\end{array}$ \\
\hline Epiphora & $37(74 \%)$ & $51(76 \%)$ \\
\hline Epiphora + mucocoele & $5(10 \%)$ & $9(13 \%)$ \\
\hline Epiphora + dacryocystitis & $5(10 \%)$ & $7(11 \%)$ \\
\hline $\begin{array}{l}\text { Epiphora }+ \text { mucocoele }+ \\
\text { dacryocystitis }\end{array}$ & $1 \quad(2 \%)$ & 0 \\
\hline Mucocoele alone & $2 \quad(4 \%)$ & 0 \\
\hline Total & $50(100 \%)$ & $67(100 \%)$ \\
\hline
\end{tabular}

Values are the number (\%) of procedures performed.

developed a peribulbar haemorrhage with a marked reduction in visual acuity. This was managed by orbital compression with a mercury bag (as described for retrobulbar haemorrhage in cataract surgery ${ }^{17}$ ), and fortunately resolved rapidly with no long-term sequelae. There were no cases of per- or postoperative nasal haemorrhage.

At the first post-operative visit, 29 (59\%) patients were asked for their opinion of the procedure. Twenty-six $(90 \%)$ found it entirely acceptable. The most unpleasant aspect was the tapping sound heard internally produced by the laser, especially during bone removal. After a mean follow-up of 4.0 (1.5) months, $35(70 \%)$ procedures were successful in resolving symptoms. The 2 patients without epiphora were judged as successes based on complete resolution of their mucocoele.

Twenty-eight procedures (56\%) employed tubes and $22(44 \%)$ did not. There were no significant differences between these two subgroups for all analyses, apart from a higher volume of LA being used in the former (6.4 (1.6) versus $5.3(1.0) \mathrm{ml}$ respectively, $p<0.05)$. However, more procedures with tubes were successful compared with those without (22 (79\%) compared with 13 (59\%) respectively), although the difference did not achieve statistical significance. Both subgroups had a similar duration of follow-up (4.0 (1.1) versus 4.1 (2.0) months, respectively).

\section{Conventional DCR}

Over the 2 year study period, 67 patients underwent conventional DCR. There were 24 men and 43 women and their mean age was 60.8 (18.7) years. Their indications for surgery are also shown in Table I. No patient had daycase surgery and the mean inpatient stay was $2.3(0.7)$ days. All procedures except 1 were performed under general anaesthesia. The mean operation time was 67.4 (25.5) minutes. There were no per- or post-operative complications recorded.

Fifty-four $(81 \%)$ cases were successful in relieving symptoms, after a mean follow-up of 4.5 (7.0) months. Ten patients $(15 \%)$ received tubes and 57 $(85 \%)$ did not. These two subgroups were also 
similar for all details, with comparable success rates (7 $(70 \%)$ and $47(83 \%)$ respectively).

The two groups undergoing either ELDCR or conventional DCR were similar as regards sex distribution, age, indications for surgery and followup. Of note were the significantly lower operative time $(p<0.00001)$ and the much higher frequency of LA and daycase surgery in the ELDCR group.

When comparing the outcomes of the two surgical groups, no differences were noted except for a significantly higher success rate in conventional DCRs without tubes compared with ELDCRs without tubes $(p<0.05)$. The mean follow-up was similar in these subgroups.

\section{DISCUSSION}

We are only the second group to report on endonasal laser DCR with the holmium:YAG laser. The initial study ${ }^{15}$ consisted of 40 primary procedures in 37 patients and their functional success rate was $82 \%$, but all patients received stents. This success rate is not dissimilar to our findings in the subgroup of patients who underwent naso-lacrimal intubation $(79 \%)$. However, there are certain other differences between the two reports. In Woog and colleagues' study ${ }^{15}$ surgery was performed under either general anaesthesia or LA with intravenous sedation, whereas all but 1 of our cases were performed under simple LA. Also, bone removal was augmented with use of a small drill in $15(38 \%)$. In contrast, we used the holmium:YAG laser alone for bone removal in all cases. In the 25 procedures where bone removal was with the laser alone, Woog et al. ${ }^{15}$ reported a success rate of $72 \%$ (18 cases) - not dissimilar to the findings in our comparable subgroup.

The same group later reported on a slightly enlarged study population (46 procedures in 40 patients), ${ }^{16}$ and found a success rate of $85 \%$. Their mean operating time was considerably longer than in our study (116 minutes versus 21 minutes, respectively), but in 37 cases they performed additional procedures (anterior or posterior ethmoidectomy, middle turbinate resection or septoplasty). ${ }^{16}$ Also, 6 patients underwent conjunctivodacryocystorhinostomy with a Jones tube rather than a simple DCR.

The other reports of ELDCR utilised either a high-energy argon laser ${ }^{13}$ (following the original description of this new technique ${ }^{12}$ ) or either the carbon dioxide or PTP lasers. ${ }^{14}$ Boush and colleagues $^{13}$ employed the argon laser and reported an overall success rate of $70 \%$ in 46 single procedures after a mean follow-up of 6 months. However, 53 cases were attempted and $7(13 \%)$ required conversion to surgical DCR, based on various factors identified during the procedure. Again, all their patients received stents and were also treated with both topical ocular and nasal steroids. Surgery was performed under either general anaesthesia or LA with intravenous sedation. Gonnering and coworkers $^{14}$ used both the carbon dioxide and PTP lasers for either standard DCRs (15 cases) or conjunctivodacryocystorhinostomy with a Lester Jones tube (5 cases). They reported a $100 \%$ success rate in relief of symptoms after a mean follow-up of 6.3 months. All patients undergoing ELDCR alone received tubes. Again, surgery was performed under LA with intravenous sedation or general anaesthesia.

None of the previous reports of ELDCR ${ }^{13-16}$ compared their results with conventional DCR, other than those published in the literature. The usually-cited success rates of $90 \%$ often come from those who specialise in lacrimal surgery. ${ }^{2,3,6-10}$ Although we have not performed a randomised prospective study of the two techniques (which would have proved impossible, given the level of local interest in ELDCR amongst both patients and doctors), we have compared our results with a similar-sized sample who underwent conventional primary DCRs in our unit over the preceding 2 years. Surgery was performed by all consultant teams, and perhaps reflects more closely the results found in units that lack a specialist lacrimal surgeon. The two groups were comparable for age, sex and the indications for surgery. Overall, the functional success rates were not dissimilar, after similar periods of follow-up. The main differences lie in anaesthesia (invariably general for conventional DCRs), the much shorter operating time for ELDCRs and the duration of hospital stay (none of the conventional DCRs were performed as daycases).

There was a definite learning curve with ELDCR. The operative time showed a significant fall with time $(r=-0.386, p<0.02)$, although the laser energy did not demonstrate a similar fall. Neither the time nor the laser energy was related to the patient's age, but there was a significant increase in laser energy with increasing operative time $(r=0.518, p<0.001)$. This has not been commented on in previous reports of ELDCR,${ }^{13-16}$ although Gonnering and colleagues do comment on the learning curve for video endoscopy. ${ }^{14}$ Not surprisingly, the conventional DCR group did not exhibit a similar learning curve.

Standard teaching of conventional DCRs requires a large bony ostium to be created. The original description of ELDCR in cadavers produced a smaller bony ostium 5-7 mm in diameter. ${ }^{12}$ Boush and colleagues ${ }^{13}$ created a vertically oval ostium 10 $\times 15 \mathrm{~mm}$ and Woog and coworkers ${ }^{15}$ made an opening of between 5 and $10 \mathrm{~mm}$ using ELDCR. We did not measure the ostium accurately, although it was adequate to allow easy passage of the vitreoretinal light probe. However, Linberg et al. ${ }^{18}$ used 
endoscopy to study the healed intranasal ostium following conventional DCR, and found an average opening of $1.8 \mathrm{~mm}$ in diameter. This was not related to the size of the ostium created during surgery, which was $11.8 \mathrm{~mm}$ in diameter on average. Interestingly, all 22 patients in this study were asymptomatic. Thus, the size of the ostium per se does not seem to influence the outcome. The previous studies of ELDCR ${ }^{13-16}$ did not include a subgroup who were not intubated. However, we found a trend towards an improved success rate following ELDCR when naso-lacrimal intubation was performed, and patients undergoing conventional DCR without tubes in our study had a significantly higher success rate than did those undergoing ELDCR without tubes. This suggests that intubation of the naso-lacrimal system following ELDCR may be of importance in achieving functional success.

A non-laser transnasal approach to DCR has recently been reported. ${ }^{19}$ The authors studied 19 patients who underwent an endoscopic transnasal DCR, with excellent results (a $94.7 \%$ symptomatic success rate, with a follow-up of over 9 months). All procedures were performed under general anaesthesia. Nasal mucosal flaps are created, and bone removed (with a drill or hammer, gouge and rongeurs if the frontal process of the maxilla interfered with exposure) and an anterior resection of the middle turbinate may be required. The nasolacrimal sac was then tented with a lacrimal cannula and incised and all patients were intubated. ${ }^{19}$

This rhinological approach is considerably more complex and invasive than that with the holmium:YAG laser and presumably takes longer to perform (although operative time was not commented $\left.{ }^{19}{ }^{19}\right)$. Another difference is the use of general anaesthesia, precluding the daycase approach adopted in our study (although the authors suggest that a daycase approach may be feasible with their technique $^{19}$ ). However, their success rate is better than that found in our study, although all their patients received stents. ${ }^{19}$ It is obvious that further work is required to identify the best technique for the endonasal approach to lacrimal surgery.

In conclusion, our initial results following ELDCR were comparable to those of conventional DCR performed in our unit, with an overall success rate of $70 \%$. Naso-lacrimal intubation improved this to $79 \%$. This technique can readily be performed under LA as a daycase procedure, and is acceptable to the majority of patients. In addition, surgery is faster with ELDCR compared with conventional DCR.

Key words: Dacryocystorhinostomy, Endoscopic, Holmium: YAG, Laser, Outpatient procedure.

\section{REFERENCES}

1. Toti A. Nuovo metodo conservatore dicura radicale delle soppurazioni croniche del sacco lacrimale (dacriocistorinostomia). Clin Moderna (Firenza) 1904; 10:385-7.

2. Romanes GJ. Dacryocystorhinostomy: clinical report of fifty cases. Br J Ophthalmol 1955;39:237-40.

3. McPherson SD, Egleston D. Dacryocystorhinostomy: a review of 106 operations. Am J Ophthalmol 1959; 47:328-31.

4. Moore JG. Dacryocystorhinostomy with intubation of both canaliculi. Trans Ophthalmol Soc UK 1967; 87:831-3.

5. Moore JG. Dachryocystorhinostomy with intubation. Trans Ophthalmol Soc UK 1968;88:523-5.

6. Iliff CE. A simplified dacryocystorhinostomy. Arch Ophthalmol 1971;85:586-91.

7. Pico G. A modified technique of external dacryocystorhinostomy. Am J Ophthalmol 1971;72:679-90.

8. Welham RAN, Henderson PH. Results of dacryocystorhinostomy: analysis of causes of failure. Trans Ophthalmol Soc UK 1973;93:601-9.

9. McLachlan DL, Shannon GM, Flanagan JC. Results of dacryocystorhinostomy: analysis of the reoperations. Ophthalmic Surg 1980;11:427-30.

10. Burns JA, Cahill KV. Modified Kinosian dacryocystorhinostomy: a report of 122 cases. Ophthalmic Surg 1985;16:710-6.

11. Caldwell GW. Two new operations for obstruction of the nasal duct with preservation of the canaliculi, and an incidental description of a new lacrymal probe. N Y Med J 1893;57:581.

12. Massaro BM, Gonnering RS, Harris GJ. Endonasal laser dacryocystorhinostomy: a new approach to nasolacrimal duct obstruction. Arch Ophthalmol 1990;108:1172-6.

13. Boush GA, Lemke BN, Dortzbach RK. Results of endonasal laser-assisted dacryocystorhinostomy. Ophthalmology 1994;101:955-9.

14. Gonnering RS, Lyon DB, Fisher JC. Endoscopic laserassisted lacrimal surgery. Am J Ophthalmol 1991; 111:152-7.

15. Woog JJ, Metson R, Puliafito CA. Holmium:YAG endonasal laser dacryocystorhinostomy. Am J Ophthalmol 1993;116:1-10.

16. Metson R, Woog JJ, Puliafito CA. Endoscopic laser dacryocystorhinostomy. Laryngoscope 1994;104: 269-74.

17. Cionni RJ, Osher RH. Retrobulbar haemorrhage. Ophthalmology 1991;98:1153-5.

18. Lindberg JV, Anderson RL, Bumstead RM, Barreras R. Study of intranasal ostium external dacryocystorhinostomy. Arch Ophthalmol 1992;100:1758-62.

19. Whittet HB, Shun-Shin GA, Awdry P. Functional endoscopic transnasal dacryocystorhinostomy. Eye 1993;7:545-9. 